\title{
A retrospective case-control study investigating the association between pollutant exposures and childhood asthma
}

\author{
J. Lai, S. Julious, S. Mason \& J. Freeman \\ School of Health and Related Research, University of Sheffield, UK
}

\begin{abstract}
Objective: to investigate possible associations between daily counts of schoolage asthma-medical contacts (and controls) and daily measures of pollution in Scotland. Study design: retrospective case-control study. Methods: daily counts and daily measures were obtained from 01/01/1999 to 31/12/2004. Autoregressive models using a Poisson distribution were undertaken on three groups: cases (school age-asthmatics), controls (cases and controls were matched by age, gender, primary care practice) and on the excess of daily counts for cases over controls. Twenty-one pollutant measures were investigated. These included minimum, mean and maximum daily measures of $\mathrm{NO}, \mathrm{NO}_{2}, \mathrm{NOD}, \mathrm{PM}_{10}, \mathrm{O}_{3}$, $\mathrm{CO}, \mathrm{SO}_{2}$. Exposures were delayed by seven days to investigate any lagged effects with daily counts. Covariates include day of the week, bank holiday and season. The effects of each pollutant exposure were investigated using an F-test. Results: five pollutant exposures were associated with the daily counts for cases; six exposures were associated with daily counts for controls and eight exposures were associated with the daily excess of cases over controls. $\mathrm{NO}_{2}$ Mean was the most statistically significant exposure for cases and the excess whilst $\mathrm{SO}_{2}$ Maximum was the most statistically significant exposure for controls. Estimates were most significant after a delay (from exposure) of five (cases), four (controls) and current (excess) day(s) (lagged effect).

Keywords: asthma, child, medical contact, pollutants, autoregression.
\end{abstract}

\section{Introduction}

The prevalence of asthma (a chronic condition that affects the airways [1]) has increased substantially over the past five decades (1955-2004) [2]. The 
observed increase in the asthma prevalence is not solely the result of improved diagnosis [3] or due to any change in the genetic susceptibility [4]. It is most likely to be the consequence of the apparent changes in lifestyle and environmental quality [5].

A large number of studies have investigated the association between pollutant exposures and childhood asthma resulting in medical contact [6-31]. The studies offer substantial evidence in support of an association between pollutant exposures (for example, Nitrogen Dioxide, Sulphur Dioxide, Ozone, Particulate Matter and Carbon Monoxide) in relation to childhood asthma resulting in medical contact. A number of the studies also report delayed associations from exposure to the event of medical contact $[7,8,19]$.

From a UK perspective, a weakness from literature includes the fact that few studies were set within the UK - as pollutant measures vary vastly according to different settings, it is difficult to apply findings from research set in different locations. Another limitation of the literature is that the majority of the studies analyse hospital data which tend to capture the most severe cases of asthma. One additional constraint is that a number of studies suggest that there are a number of (indirect) effects from school return on childhood asthma [32-34] yet few studies solely use school-age children as their sample of interest. Therefore we aim using data at general practice (primary care) level to investigate possible associations between daily counts of school-age asthma-medical contacts (and controls) and daily measures of pollution in Scotland. We shall also investigate any delayed effect from exposure to pollutant measures on daily counts of medical contact.

\section{Methods}

\subsection{Data}

\subsubsection{Clinical data}

Data were sourced from the General Practice Research Database (GPRD). Ethics approval to use the data was obtained via the GPRD. The sample consisted age, gender and practice matched cases and controls. The sample included children aged five to sixteen years of age. Cases were defined as patients with a medical diagnosis of asthma. Controls were selected with no medical record of asthma. We also investigated the excess (difference between cases and controls) as a third group in our investigation.

Daily counts were captured from the $01 / 01 / 1999$ to $31 / 12 / 2004$. The $29^{\text {th }}$ of February from any leap year was omitted from analysis. Also, Christmas Day and New Year's Day were omitted from the analysis as daily counts on these days were extremely low thus may biased results. Three additional outlying (residuals $<4$ or $>-4$ ) dates were also omitted from the analysis (after investigation it seemed on these dates there was retrospective data entry). These dates were 04/02/2002; 27/11/2002 and 26/09/2003.

Daily counts comprised of a number of medical contacts: Acute Visits - house calls made by the General Practitioner (GP); Casualty Contacts - attendance to 
an Accident and Emergency department; Emergency Consultations - Open surgery or emergency appointments by the GP in normal working hours; Out of Hours Contacts - Out of Hours defined from 6.30pm to 8am during weekdays, weekends and bank holidays. These medical contacts are not mutually exclusive. All medical contacts bar Casualty counts were GP related medical contacts. All Counts that encapsulate all groups of medical contact are reported in this investigation.

\subsubsection{Environmental data}

Data for environmental exposures were obtained from the National Air Archive for the location of Aberdeen, Scotland. Daily minimum (lowest measure on the day), mean and maximum (highest measure on the day) measures were obtained from the $01 / 01 / 1999$ to $31 / 12 / 2004$. We obtained measures on the following pollutants: Nitric Oxide (NO), Nitrogen Dioxide $\left(\mathrm{NO}_{2}\right)$, Nitrogen Oxides of Dioxide (NOD), Sulphur Dioxide $\left(\mathrm{SO}_{2}\right)$, Particulate Matter $10\left(\mathrm{PM}_{10}\right)$, Ozone $\left(\mathrm{O}_{3}\right)$ and Carbon Monoxide (CO). $\mathrm{NO}_{2}, \mathrm{NO}, \mathrm{NOD}, \mathrm{O}_{3}$ and $\mathrm{SO}_{2}$ were measured in $\mathrm{ugm}^{3}, \mathrm{CO}$ was measured in $\mathrm{mgm}^{3}$ and $\mathrm{PM}_{10}$ was measured in $\mathrm{ugm}^{3}$ (GRAV-EV).

\subsection{Statistical analysis}

Analyses of the data were completed in STATA 11 and Microsoft Excel 2007. We investigated whether environmental exposures have an effect on the number of asthmatic episodes (alternative hypothesis) in comparison to whether environmental exposures had no effect on the number of asthmatic episodes (null hypothesis). Autoregressive models using a log-linear Poisson distribution [35] were implemented. Autocorrelation present with a seven day lag due to a day of the week influence on daily counts. Therefore, we fitted an autoregressive term seven to allow for seventh order autocorrelation.

The null model included day of the week (Monday to Saturday), bank holiday and four sinusoidal terms to account for season. The alternative model included all the covariates used in the null model together with each pollutant variable in turn. Each pollutant variable were analysed separately with its seven lagged terms. We tested the fit of the alternative model (including the environmental variables) against the null model using an F-test of the change in deviance [36].

The P-value for the F-test statistic was calculated using the FDIST function in Excel. Statistical significance of each model was set at $5 \%$.

In addition to investigating the fit of the overall model, using the pollutant point estimates corresponding P-values, we assessed the most significant lag day (need not be statistically significant) and the distribution of the P-values.

\section{Results}

A total of 8726 age, gender and practiced matched cases and controls were included.

Table 1 illustrates the results from the comparison of the alternative against the null model. For cases, in comparison to the null model, five models including 
Table 1: $\quad$ F-test P-values.

\begin{tabular}{|c|c|c|c|c|c|c|}
\hline \multirow[b]{2}{*}{ Variable } & \multicolumn{2}{|c|}{ Cases } & \multicolumn{2}{|c|}{ Controls } & \multicolumn{2}{|c|}{ Excess } \\
\hline & F-value & P-value & F-value & P-value & F-value & P-value \\
\hline NO Minimum & 0.38 & 0.93 & 0.55 & 0.82 & 0.58 & 0.80 \\
\hline $\mathrm{NO}_{2}$ Minimum & 2.21 & $* 0.02$ & 0.58 & 0.80 & 3.65 & $* 0.00$ \\
\hline NOD Minimum & 1.61 & 0.12 & 2.10 & $* 0.03$ & 2.15 & $* 0.03$ \\
\hline $\mathrm{SO}_{2}$ Minimum & 0.46 & 0.89 & 1.96 & $* 0.05$ & 0.25 & 0.98 \\
\hline $\mathrm{PM}_{10}$ Minimum & 1.24 & 0.27 & 1.63 & 0.11 & 1.98 & $* 0.05$ \\
\hline $\mathrm{O}_{3}$ Minimum & 0.82 & 0.58 & 1.15 & 0.32 & 0.80 & 0.60 \\
\hline CO Minimum & 2.07 & $* 0.04$ & 0.62 & 0.76 & 1.88 & 0.06 \\
\hline NO Mean & 0.64 & 0.74 & 0.83 & 0.57 & 1.18 & 0.31 \\
\hline $\mathrm{NO}_{2}$ Mean & 3.11 & $* * 0.00$ & 0.50 & 0.86 & 4.67 & $* * 0.00$ \\
\hline NOD Mean & 1.36 & 0.21 & 1.06 & 0.39 & 2.89 & $* 0.00$ \\
\hline $\mathrm{SO}_{2}$ Mean & 1.27 & 0.26 & 2.87 & $* 0.00$ & 0.55 & 0.82 \\
\hline $\mathrm{PM}_{10}$ Mean & 2.83 & $* 0.00$ & 1.46 & 0.17 & 4.26 & $* 0.00$ \\
\hline $\mathrm{O}_{3}$ Mean & 0.96 & 0.47 & 0.93 & 0.49 & 1.04 & 0.40 \\
\hline CO Mean & 0.03 & 1.00 & 0.30 & 0.97 & 0.73 & 0.66 \\
\hline NO Maximum & 0.65 & 0.74 & 1.97 & $* 0.05$ & 1.00 & 0.43 \\
\hline $\mathrm{NO}_{2}$ Maximum & 2.19 & $* 0.03$ & 1.06 & 0.39 & 2.70 & $* 0.01$ \\
\hline NOD Maximum & 0.65 & 0.74 & 2.21 & $* 0.02$ & 2.22 & $* 0.02$ \\
\hline $\mathrm{SO}_{2}$ Maximum & 1.83 & 0.07 & 3.19 & $* * 0.00$ & 0.85 & 0.56 \\
\hline $\mathrm{PM}_{10}$ Maximum & 0.28 & 0.97 & 1.76 & 0.08 & 1.59 & 0.12 \\
\hline $\mathrm{O}_{3}$ Maximum & 1.14 & 0.34 & 0.56 & 0.81 & 1.11 & 0.35 \\
\hline CO Maximum & -0.30 & 1.00 & 1.60 & 0.12 & 0.45 & 0.89 \\
\hline
\end{tabular}

** Most significant P-value out of 21 triggers

* Statistically significant model

pollutant variables lagged by seven days was observed to have an improved fit that was statistically significant. For controls, six models and for the excess between cases and controls, eight models were found to have an improved fit to the data that was statistically significant.

Table 1 also indicates the pollutant variables with the smallest P-values. Among all pollutant measures investigated, for cases and the excess of cases over controls, the model including mean measures of $\mathrm{NO}_{2}$ was that most statistically significant model. For controls, the model including maximum measures of $\mathrm{SO}_{2}$ was the most statistically significant model.

Figure 1 illustrates frequency distributions of the F-test P-values from all models including pollutant variables. A uniformed distribution with a mean (p) value of 0.5 or higher infers that pollutant triggers have no association on the daily count of medical contacts. A positive distribution infers that pollutant 
triggers have a positive association with daily counts of medical contact and negative distributions suggest the opposite. Figure 1 demonstrates positive distributions for all three groups investigated though the severity of the skewness varies. The strongest association from pollutants is observed on the excess between cases and controls (Figure 1c). Figure 1a shows that cases have the weakest positive distribution. In comparison to controls (Figure 1b) that have a stronger positive distribution, it appears that pollutant exposures have a stronger association with the controls group rather than asthmatics.
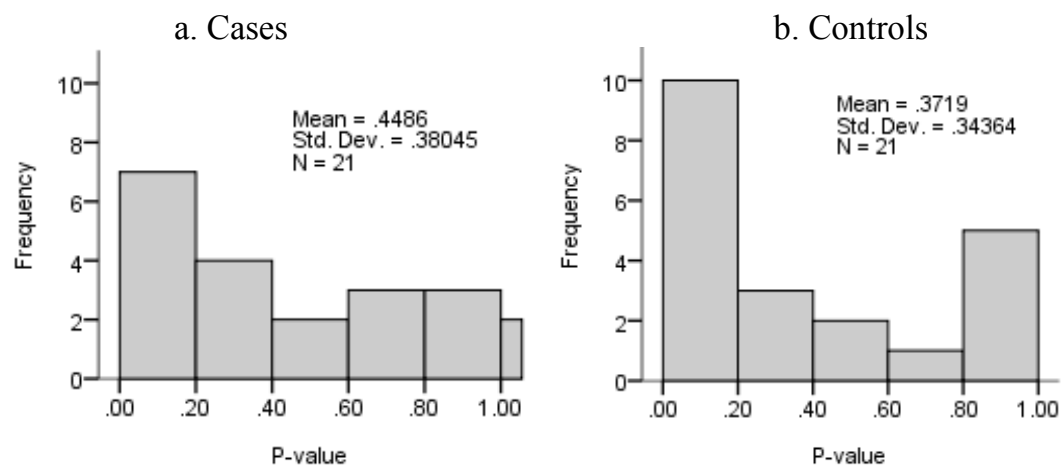

c. Excess

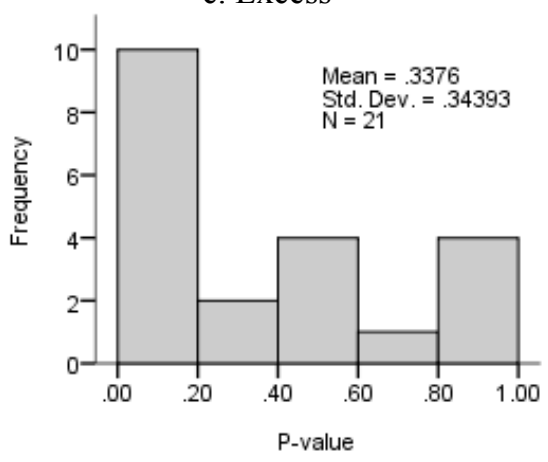

Figure 1: F-test P-value histograms a. Cases, b. Controls, c. Excess.

To illustrate whether there is a delayed (lagged) effect from environmental exposures, Figure 2 demonstrates the frequency of most significant point estimates among the lag day ( 0 to 7$)$ per environmental variable. The most significant lag day was lag day five, lag day four and current day for cases, controls and the excess respectively.

Figure 3 illustrates the point estimate P-values histograms. The pollutant point estimate P-values from each group is fairly uniformly distributed. Once more, for cases and the excess, the mean P-value is higher than 0.5 inferring no association from exposure to pollutants and daily counts of medical contact. 
a) Cases

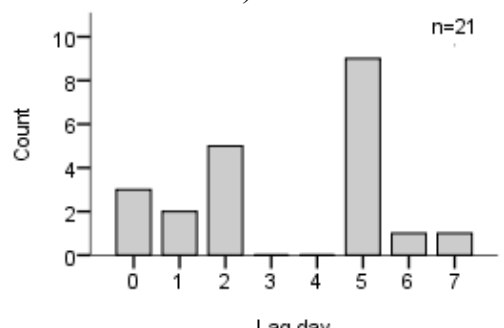

b) Controls

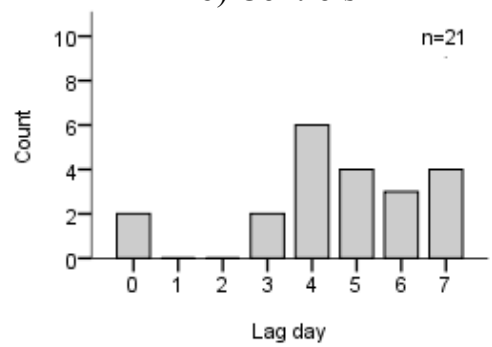

c) Excess

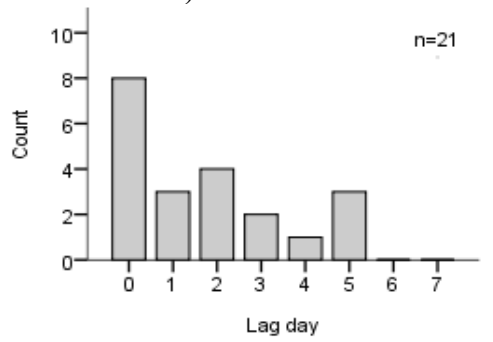

Figure 2: Number of the most significant point-estimates per pollutant variable by lag day a) Cases, b) Controls and c) Excess.
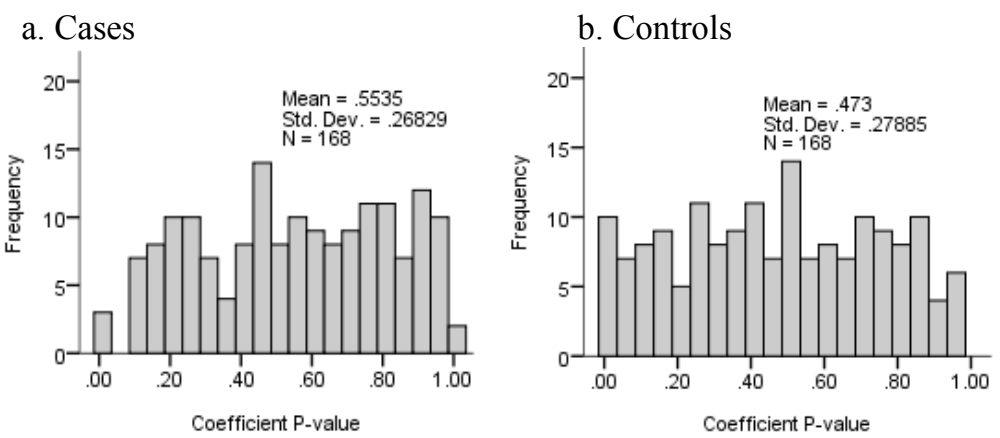

c. Excess

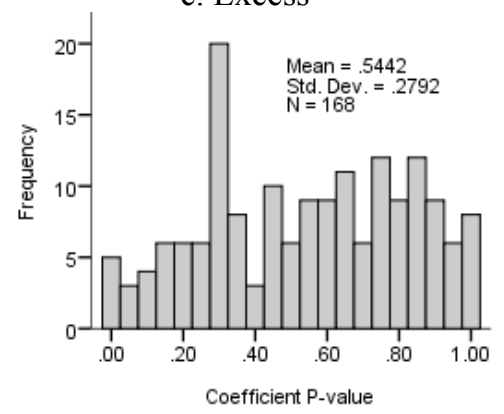

Figure 3: Point estimate P-value histograms a. Cases, b. Controls, c. Excess. 


\section{Discussion}

\subsection{Summary of results}

The overall model P-values suggest that a number of pollutant exposures are linked to daily counts of medical contact. Yet, these results infer a stronger association on controls rather than asthmatics. Results from the point-estimates $\mathrm{P}$-values show that there is a delayed effect from exposure to pollutant measures and daily counts of medical contact in cases and controls but not in the excess. Results are not constant within this investigation; the uniformed distribution of the point-estimates P-values (from the pollutants only) demonstrates no association/effect from pollutant measures on daily counts of medical contact.

\subsection{Strengths and weakness of the investigation}

We have been able to illustrate the relationship over time between pollutant exposures and daily counts of medical contact using a large sample of age, gender and practiced matched cases and controls. However, a weakness on this investigation is that we applied small area pollutant measures to a large area population outcome. Thus we are assuming that pollutant measures in one area are typical of the whole country which is often not the case. Another weakness that relates to the first limitation is that we have not been able to control for factors that mitigate pollutant exposure such as the role of wind in the dispersion of pollution and pollutant sources. In effect, we have not been able to account for the spatial characteristics of pollution.

\section{Conclusion}

This study provides evidence to link certain pollutant exposures to the daily number of unscheduled medical contacts made by school-age asthmatics, controls and the excess between cases and controls. Literature illustrates that asthma places a heavy burden on the individual, carers and also places profound demand on health services.

At the moment, due to the weaknesses of this investigation, caution must be applied to the interpretation of these results. We have found some evidence to suggest a link between particular pollutant exposures and daily counts of medical contact in cases, controls and the excess between. However, these results were not constant throughout our investigation. Nevertheless, findings from this research can aid in the construction of preventive strategies to reduce number of asthmatic attacks.

\section{References}

[1] World Health Organisation. Asthma Factsheet. http://www.who.int /mediacentre/factsheets/fs307/en/index.html.

[2] Anderson, H. R., "Prevalence of Asthma", BMJ, vol. 330, pp. 1038-1039, 2005. 
[3] Burnley, P. G. J., Chinn, S., \& Rona, R. J. "Has the prevalence of asthma increased in children? Evidence from the National Study of Health and Growth", British Medical Journal, vol. 300, pp. 1306-1310, 1990.

[4] Seaton, A., Godden, D. J., \& Brown, K. "Increase in asthma: a more toxic environment or a more susceptible population?", Thorax, vol. 49, pp. 171174, 1994.

[5] von Mutius, E. "The burden of childhood asthma", Archives of Disease in Childhood, vol. 82, p. S2-S5, 2000.

[6] Barnett, A. G., Williams, G. M., Schwartz, J., Neller, A. H., Best, T. L., Petroeschevsky, A. L., Simpson, R. W. "Air pollution and child respiratory health: a case-crossover study in Australia and New Zealand", American Journal of Respiratory \& Critical Care Medicine, vol. 171, no. 11, pp. 1272-1278, 2005.

[7] Buchdahl, R., Willems, C. D., Vander, M., \& Babiker, A. “Associations between ambient ozone, hydrocarbons, and childhood wheezy episodes: a prospective observational study in south east London", Occupational and Environmental Medicine, vol. 57, no. 2, pp. 86-93, 2000.

[8] Chew, F. T., Goh, D. Y. T., Ooi, B. C., Saharom, R., Hui, J. K. S., \& Lee, B. W. "Association of ambient air-pollution levels with acute asthma exacerbation among children in Singapore", Allergy, vol. 54, no. 4, pp. 320-329, 1999.

[9] English, P., Neutra, R., Scalf, R., Sullivan, M., Waller, L., \& Zhu, L., "Examining associations between childhood asthma and traffic flow using a geographic information system", Environmental Health Perspectives, vol. 107, no. 9, pp. 761-767, 1999.

[10] Erbas, B., Kelly, A. M., Physick, B., Code, C., Edwards, M., “Air pollution and childhood asthma emergency hospital admissions: estimating intra-city regional variations", International Journal of Environmental Health Research, vol. 15, no. 1, pp. 11-20, 2005.

[11] Fauroux, B., Sampil, M., Quenel, P., \& Lemoullec, Y. "Ozone: a trigger for hospital pediatric asthma emergency room visits", Pediatric Pulmonology, vol. 30, no. 1, pp. 41-46., 2000.

[12] Garty, B. Z., Kosman, E., Ganor, E., Berger, V., Garty, L., Wietzen, T., Waisman, Y., Mimouni, M., Waisel, Y. "Emergency room visits of asthmatic children, relation to air pollution, weather, and airborne allergens", Annals of Allergy, Asthma, \& Immunology, vol. 81, no. 6, pp. 563-570, 1998.

[13] Hirshon, J. M., Shardell, M., Alles, S., Powell, J. L., Squibb, K., Ondov, J., \& Blaisdell, C. J. "Elevated ambient air zinc increases pediatric asthma morbidity", Environmental Health Perspectives, vol. 116, no. 6, pp. 826831, 2008.

[14] Jalaludin, B., Khalaj, B., Sheppeard, V., \& Morgan, G. "Air pollution and ED visits for asthma in Australian children: a case-crossover analysis", International Archives of Occupational and Environmental Health, vol. 81, no. 8, pp. 967-974, 2008. 
[15] Kuo, H. W., Lai, J. S., Lee, M. C., Tai, R. C., Lee, M. C. "Respiratory effects of air pollutants among asthmatics in central Taiwan", Archives of Environmental Health, vol. 57, no. 3, pp. 194-200, 2002.

[16] Lee, J. T., Kim, H., Song, H. Y., Hong, Y. C., Cho, Y. S., Shin, S. Y., Hyun, Y. J., \& Kim, Y. S. "Air pollution and asthma among children in Seoul, Korea”, Epidemiology, vol. 13, no. 4, pp. 481-484, 2002.

[17] Lee, S. L., Wong, W. H. S., \& Lau, Y. L. "Association between air pollution and asthma admission among children in Hong Kong”, Clinical and Experimental Allergy, vol. 36, no. 9, pp. 1138-1146, 2006.

[18] Lin, C. A., Martins, M. A., Farhat, S. C. L., Pope, C. A., Conceicao, G. M. S., Anastacio, V. M., Hatanaka, M., Andrade, W. C., Hamaue, W. R., Bohm, G. M., \& Saldiva, P. H. N. "Air pollution and respiratory illness of children in Sao Paulo, Brazil", Paediatric and Perinatal Epidemiology, vol. 13, no. 4, pp. 475-488, 1999.

[19] Lin, M., Chen, Y., Burnett, R. T., Villenueve, P. J., \& Krewski, D. "Effect of short term exposure to gaseous pollution on asthma hospitalisation in children: a bi-directional case-crossover analysis.", Journal of Epidemiology and Community Health, vol. 57, pp. 50-55, 2003.

[20] Lin, M., Chen, Y., Burnett, R. T., Villeneuve, P. J., \& Krewski, D. "The influence of ambient coarse particulate matter on asthma hospitalization in children: Case-crossover and time-series analyses", Environmental Health Perspectives, vol. 110, no. 6, pp. 575-581, 2002.

[21] Lin, S., Liu, X., Le, L. H., Hwang, S. A., Lin, S., Liu, X., Le, L. H., \& Hwang, S. A. "Chronic exposure to ambient ozone and asthma hospital admissions among children", Environmental Health Perspectives, vol. 116, no. 12, pp. 1725-1730, 2008.

[22] Magas, O. K., Gunter, J. T., Regens, J. L., Magas, O. K., Gunter, J. T., \& Regens, J. L. "Ambient air pollution and daily pediatric hospitalizations for asthma", Environmental Science \& Pollution Research, vol. 14, no. 1, pp. 19-23, 2007.

[23] Magliaretti, G. \& Cavallo, F. "Urban Air pollution and asthma in children”, Pediatric Pulmonology, vol. 38, pp. 198-203, 2004.

[24] Moore, K., Neugebauer, R., Lurmann, F., Hall, J., Brajer, V., Alcorn, S., Tager, I. "Ambient ozone concentrations cause increased hospitalizations for asthma in children: an 18-year study in Southern California", Environmental Health Perspectives, vol. 116, no. 8, pp. 1063-1070, 2008.

[25] Norris, G., YoungPong, S. N., Koenig, J. Q., Larson, T. V., Sheppard, L., Stout, J. W. "An association between fine particles and asthma emergency department visits for children in Seattle", Environmental Health Perspectives, vol. 107, no. 6, pp. 489-493, 1999.

[26] Paliatsos, A. G., Prifris, K. N., Ziomad, I. C., Panagiotopoulou-Gratagani, P., Tapratzi-Potamianou, P., Zachariadi-Xypolita, A., Nicolaidou, P., \& Saxoni-Papageorgiou, P. "Association between ambient air pollution and childhood asthma in Athens, Greece.", Fresenious Environmental Bulletin, vol. 15, no. 7, pp. 614-618, 2006. 
[27] Romieu, I., Meneses, F., Joses L, J., Sienra-Monge, Huerta, J., Velasco, S. R., White, M. C., Etzel, R. A., \& Hernandez-Avila, M.. "Effect of Urban Air Pollutants on Emergency Visits for Childhood Asthma in Mexico City", American Journal of Epidemiology, vol. 141, no. 6, pp. 546-553, 1995.

[28] Tecer, L. H., Alagha, O., Karaca, F., Tuncel, G., \& Eldes, N. "Particulate matter $\left(\mathrm{PM}_{2.5}, \mathrm{PM}_{10-2.5}\right.$, and $\left.\mathrm{PM}_{10}\right)$ and children's hospital admissions for asthma and respiratory diseases: A bidirectional case-crossover study", Journal of Toxicology and Environmental Health-Part A-Current Issues, vol. 71, no. 8, pp. 512-520, 2008.

[29] Thompson, A. J., Shields, M. D., \& Patterson, C. C. "Acute asthma exacerbations and air pollutants in children living in Belfast, Northern Ireland", Archives of Environmental Health, vol. 56, no. 3, pp. 234-241, 2001.

[30] Tolbert, P. E., Mulholland, J. A., MacIntosh, D. L., Xu, F., Daniels, D., Devine, O. J., Carlin, B. P., Klein, M., Dorley, J., Butler, A. J., Nordenberg, D. F., Frumkin, H., Ryan, P. B., White, M. C., C. "Air quality and pediatric emergency room visits for asthma in Atlanta, Georgia, USA", American Journal of Epidemiology, vol. 151, no. 8, pp. 798-810, 2000.

[31] Wong, G. W. K., Ko, F. W. S., Lau, T. S., Li, S. T., Hui, D., Pang, S. W., Leung, R., Fok, T. F., \& Lai, C. K. W. "Temporal relationship between air pollution and hospital admissions for asthmatic children in Hong Kong”, Clinical and Experimental Allergy, vol. 31, no. 4, pp. 565-569, 2001.

[32] Johnston, N.W., Johnston, S.L., Norman, G.R., Dai, J., \& Sears, M.R. "The September epidemic of asthma hospitalisation: school as disease vectors", Journal of Allergy and Clinical Immunology, vol. 117, no. 3, pp. 557-562, 2006.

[33] Julious, S.A., Osman, L.M., \& Jiwa, M. "Increases in asthma admissions associated with the end of summer vacation for school-age children with asthma in two cities from England and Scotland", Public Health, vol. 121, no. 1, pp. 482-484, 2006.

[34] Lincoln, D., Morgan, G., Sheppeard, V., Jalaludin, B., Corbett, S., \& Beard, J. Childhood asthma and return to school in Sydney, Australia. Public Health, vol. 120, no. 9, pp. 854-862, 2006.

[35] Newton H. J. Stata Technical Bulletin November 1998. Options. 1998.

[36] Collett D. Modelling Binary Data. London: Chapman and Hall/CRC; 2002. 